\title{
Comunicação e espaço urbano: entrevista com 0 antropólogo francês Marc Augé
}

\section{Elane Peixoto e Maria da Conceição Golobovante}

\section{Resumo}

Este texto apresenta a entrevista com 0 antropólogo Marc Augé, realizada na École des Hautes Études en Sciences Sociales, Paris, quando temas como antropologia urbana, comunicação, globalização e tendências atuais do pensamento antropológico foram abordados. Nele, há um breve curriculum desse importante pensador e a entrevista na íntegra de Augé, considerando sua relevância para as áreas da Comunicação, particularmente no que diz respeito à complexidade das cidades contemporâneas.

\section{Palavras-chave}

Comunicação. Cultura urbana. Audiovisual. Cidade contemporânea.

\section{Elane Peixoto | elanerib@hotmail.com}

Doutora em Estruturas Ambientais e Urbanas pela Faculdade de Arquitetura e Urbanismo da Universidade de São Paulo - FA-USP. Professora do Programa de Pós-graduação em Desenvolvimento e Planejamento Territorial da Universidade Católica de Goiás - UCG.

\section{Maria da Conceição Golobovante | mccgo|@pucsp.br}

Doutora em Comunicação e Semiótica pela Pontifícia Universidade Católica de São Paulo - PUC-SP. Professora do Centro Universitário Belas Artes e da PUC-SP.

Trabalho apresentado no âmbito do Núcleo de Pesquisa Comunicação e Culturas Urbanas no XXX Congresso Brasileiro de Ciências da Comunicação - INTERCOM, 2007. Tradução aprimorada e revista.
A perspectiva interdisciplinar é a tônica dominante das pesquisas teóricas e empíricas das ciências sociais contemporâneas, 0 que inspira alguma cautela, pois é fato que boa parte do conhecimento científico e universitário hegemônico é historicamente fundada no compartilhamento disciplinar rígido, sendo refratário ao hibridismo dos procedimentos das pesquisas empreendidas nas fronteiras disciplinares.

0 pensamento de Marc Augé acerca de uma antropologia dos mundos contemporâneos influenciou sobremaneira as teses escritas por uma arquiteta e uma publicitária que tematizaram a cidade e as transformações engendradas no meio urbano pela lógica do capital. A publicação desta entrevista na revista eletrônica da Compós contribui com a discussão sobre a comunicação e experiência urbana, pois 0 autor descreve por via de sua própria trajetória o deslocamento de campo efetuado por sua geração e também por parte da Antropologia francesa do allure para 0 urbano. Não se trata do pensamento augesiano 
sedimentado apenas nos livros por ele escritos, mas de uma expressão espontânea formulada para responder ao conjunto de perguntas que parte de uma questão central: como pensar 0 contemporâneo, o urbano e a cidade tendo como elemento central o sujeito que a habita, a produz e a simboliza? Se, como afirma Augé em seu $O$ sentido dos outros, "0 indivíduo não é senão 0 entrecruzamento necessário, porém variável, de um conjunto de relações" (1999, p. 27), é em busca da compreensão sígnica e sensível desse entrecruzamento que nos lançamos sempre que pesquisamos o urbano. Afinal, como ele mesmo afirma, ao citar Mauss e Lévi-Strauss, "com a linguagem o mundo tornou-se significativo, mas nem por isso melhor conhecido" (1999, p. 32). A captura desse instantâneo e a sua divulgação procuram transcender a dimensão informativa da comunicação, ao propor algo que confere certa estabilidade a esse entrecruzamento de relações. Assim, além de dar a conhecer e aproximar as formulações de Augé de um público maior, objetiva-se pôr em relevo o vínculo construído entre seu pensamento e sua postura ética, fonte de inspiração para essas pesquisadoras que conviveram com antropólogos de uma geração humanista por excelência.

\section{Sobre Marc Augé}

Marc Augé é antropólogo e africanista, tendo realizado pesquisas na Costa do Marfim e no Togo. Foi presidente da École des Hautes Études en Sciences Sociales (EHESS), no período de
1985 a 1995, onde, atualmente, coordena o Centro de Antropologia dos Mundos Contemporâneos. A partir dos anos 1980, diversificou seus estudos, realizando pesquisas na América Latina e voltando seu interesse para as realidades do mundo contemporâneo, com seus contextos urbanos, múltiplos e imediatos. Deste interesse recente, há uma bibliografia que se tornou referência nas ciências sociais - são mais de trinta livros publicados, versando sobre diversos temas tais como o turismo, os desafios da antropologia, entre outros.

\section{A entrevista}

Marc Augé e Gérard Althabe (in memorian) são os fundadores do Centro de Antropologia dos Mundos Contemporâneos que, ligado à EHESS de Paris, foca a pesquisa das cidades por via de uma etnologia urbana. Esses autores nos concederam duas extensas entrevistas em 2002 que, por cinco anos, ficaram arquivadas em nossas estantes, mas não em nossas memórias, sendo evocadas, quando necessário, em nossas aulas e atividades de pesquisa. Neste texto, trataremos apenas da entrevista com Marc Augé, que aconteceu na sala 401 da sede da EHESS, no clássico endereço do número 54 da Boulevard Raspail. Naquele dia frio de janeiro, em uma sala de menos de dez metros quadrados, mobiliada por estantes de livros, com uma câmera de Mini-DV na mão e algumas idéias na cabeça, aguardávamos 0 encontro com 0 autor, que para nós significava um pensamento além daquele formulado em 
Não-lugares: introdução a uma antropologia da supermodernidade. A entrevista constituiu uma oportunidade para o esclarecimento de questões relativas aos complexos fenômenos que caracterizam o nosso tempo. As perguntas dirigidas a Augé foram formuladas após uma cuidadosa revisão de suas obras publicadas, o que se reveste de importância, tendo em vista que são poucos os seus livros traduzidos para o português e publicados no Brasil. Nossas áreas de formação, a Arquitetura e a Comunicação, nos conferiam uma posição particular diante de temas epistememetodológicos próprios à Antropologia e que permearam a interlocução com 0 autor.

\section{Eliane Peixoto e Maria Conceição Golobovante} - Gostaríamos de iniciar esta entrevista pedindo ao senhor que se apresentasse, referindo-se não só a sua formação acadêmica, mas também às obras e autores que contribuíram para seu pensamento.

Marc Augé - Originalmente, fiz meus estudos em letras clássicas, "l'agregation", "normale supérieur" e um pouco de filosofia. Nos anos 1960, os que se consagravam à etnologia vinham sempre de outras áreas: da história, da filosofia. Gente da minha geração, como Emmanuel Terray, era formada em campos diversos - não tinham uma formação específica em etnologia, a não ser um certificado do Musée de L’homme. Lancei-me nesta área após ter encontrado George Balandier, que me orientou para os estudos africanistas. Trabalhei pouco tempo como professor, antes de ingressar na "Orstom" - um organismo de pesquisa, cujas principais estações encontravam-se na África. Em 1965, parti para a Costa do Marfim, onde permaneci por 4 ou 5 anos. Na África trabalhei também no Togo, depois voltei para a França, para a École des Hautes Études. Continuei a estudar a África. Um pouco depois, conheci a América Latina - o que é um percurso clássico para os etnólogos. A experiência na América Latina, mesmo que não tenha realizado um trabalho específico, nutriu minha reflexão, pois, hoje, tento fazer uma antropologia mais aplicada dentro de outro contexto - um contexto mundial.

No que diz respeito à sua formação, 0 que poderíamos considerar a(s) suas(s) referências mais importantes? A passagem do mundo africano para o mundo contemporâneo? A África que conheci não era um continente separado do mundo e à margem da história. Reagia ao choque do colonialismo, às operações de desenvolvimento, entre outras coisas. Nos anos 70, havia um tipo de otimismo, sob uma perspectiva marxista e outras, cujo fundo comum era a idéia de que os países subdesenvolvidos iriam superar suas condições - estado de espírito muito diferente do atual. Havia, portanto, uma abertura para o mundo. Não encontrei uma África atemporal, eterna e primitiva. Era uma África imersa na história. Mais tarde, quando me interessei pelo mundo do consumo, dos fenômenos que marcam a modernidade atual, eu não tive o sentimento de ruptura com as minhas pesquisas na África. Na verdade, somadas a outras, elas ampliaram a minha pequena experiência para o mundo, de forma sistemática. Além do mais, a EHESS possibilitou-me o conhecimento de vários lugares e, portanto, de tomar consciência clara 
e de uma forma precoce do contexto mundial, onde todos os fenômenos locais ganham significado hoje em dia.

É importante ressaltar a experiência de campo na África como fundamental. Nesse continente, pude encontrar muitos fenômenos interessantes, que podemos classificar sob as rubricas de religião, ideologia, doença etc. Todos eles nos falam da situação atual. As sociedades estudadas haviam elaborado modelos de interpretação da individualidade, das relações sobre o sexo, havia um sistema de representação da pessoa muito elaborado. Os materiais africanos continham elementos que alimentam o diálogo com especialistas de outras áreas, como, por exemplo, os psicólogos e os psicanalistas.

A África foi uma experiência completa, histórica e contemporânea. Porque nela um movimento religioso ou político-religioso era uma reação à situação contemporânea - o que ainda continua: há profetas que falam de corpos individuais ou da sociedade em geral. Pressenti na África que os etnólogos que crêem estudar o passado - busca dificílima - de fato, são especialistas do presente. 0 interessante na experiência etnológica é que os etnólogos falam do que consideram impuro: o contato, a relação com a modernidade, a crise da família, o deslocamento de populações - mas isso é a atualidade. Marcel Mauss dizia ser necessário estudar os fenômenos sociais totais, em todos os seus aspectos. Estudar a totalidade, hoje, significa estudar a crise da sociedade e os novos contextos que lhe conferem sentido. Os etnólogos, enfim, estudaram sempre o começo e não o fim. A ilusão é a de se estudar as sociedades que morreram. Na verdade, estudase uma nova sociedade que nasce, ainda em processo de ajustamento a um novo contexto, às vezes "na dor", em situações de injustiça enorme - que estão longe de serem resolvidas, é isto que observamos. Acredito que, a qualquer momento, nos daremos conta de que a literatura etnológica é um testemunho extraordinário de um novo mundo em processo de constituição.

Atualmente, fala-se muito de mundialização, mas o colonialismo e o pós-colonialismo foram as etapas iniciais desse processo. No fundo, assistimos de nossos lugares o nascimento do planeta como mundo. É um pouco o sentimento que tive, em função dos meus deslocamentos: os grupos humanos estão preocupados com as mesmas coisas - esta é uma lição. Outra lição, depois de minhas experiências africanas, foi o privilégio dado a maneiras diversas de me expressar. Esse interesse deu-se com minha volta para Paris, quando fiz pequenos textos, que se parecem a uma etnologia parisiense, tais como: A travessia de Luxembourg $e$ Um etnólogo no metrô. É necessário compreender que estes textos revelam uma preocupação com o método. Quer dizer que eu me indagava sobre o que seria o métier de antropólogo. Para tal, colocava-me no papel do "nativo" respondendo ao etnólogo. Imaginava o que responderia se fosse indagado sobre a significação desta ou daquela coisa familiar, por exemplo, o nome de uma estação de metrô - se respondesse que o ignorava, o "etnólogo", por mim mesmo representado, acreditaria que o nativo lhe escondia algoe não é assim, necessariamente. Verifiquei, também, que as categorias de análise etnológica prestam-se bem a descrever o nosso 
próprio percurso, nas sociedades urbanas. É também um exercício de método para responder suas perguntas.

Agora, uma pergunta sobre o estilo. É fato que a formação dos pensadores sociais é muito influenciada pela literatura e pela filosofia. O senhor utiliza a expressão "etnólogo romancista" para apontar o que seria um preciosismo estilístico que camuflaria a falta de rigor teórico de uma pesquisa. Reconhecemos, nas leituras de seus textos, um estilo. Na sua prática, como se dá a relação entre o rigor científico e a busca de uma escrita?

É verdade que sempre tive o gosto pela escrita. Exprimir algo de tom pessoal, mesmo que seja da ordem da antropologia e etnologia, passa por uma expressão mais literária. Parece-me muito importante, na atualidade, afirmar que a antropologia - insisto muito no uso do termo, mais que a etnologia, pelo seu aspecto comparativo e transversal - tem o que dizer para a análise do mundo contemporâneo. À sua maneira, observando as situações locais, o antropólogo trabalha só. A princípio, ele deve dar conta dos fenômenos locais e também de tudo o que é novo no contexto. $O$ contexto, de uma parte, é o planeta inteiro, um mundo onde a circulação, a comunicação e o consumo são privilegiados. Não se pode dizer que todos consomem ou circulam na mesma proporção.

Há um sistema de valores, ambientes e um aparelho tecnológico que caminham em paralelo. Foi o que tentei mostrar em Nãolugares: há espaços inéditos no mundo atual, justamente os de circulação e consumo, sem precedentes no século anterior.
É o que o senhor chama de Mundialização? Qual a diferença em relação à Globalização?

Sempre houve mundialização e globalização. Novo é o que entendemos por mundialização-o contexto é sempre, hoje, mundial. Os impérios existiram e eram percebidos, de certa maneira, como mundo. Agora há uma coincidência entre o mundo e o planeta, enquanto corpo físico. Tomamos consciência desse fato de diversas maneiras. É necessário distinguir os termos. Globalização é sinônima de processos econômicos, mercado liberal, liberalismo triunfante, depois da derrocada do regime comunista. É também a comunicação, por meio da tecnologia, e sua a ligação intrincada com a economia. A globalização, em minha opinião, é apenas um aspecto da mundialização.

Há outros, como o que chamaria de planetarização, a consciência planetária que, por sua vez, tem pelo menos dois aspectos. Em primeiro lugar, a consciência de que pertencemos a um único planeta. A ecologia nos ajudou a tomar consciência desse fato a partir do momento em que nos preocupamos com as ameaças provenientes dos buracos nas camadas de ozônio. Estamos falando do corpo físico do planeta. Um segundo aspecto é social. É necessário ver que quanto mais o mundo se uniformiza, por meio das redes de comunicação, mais se torna desigual. Os mais ricos tornam-se cada vez mais ricos e os mais pobres cada vez mais pobres. É uma espécie de contradição entre essa aparente igualdade de um lado e desigualdade do outro. Pareceme que é necessário estar dentro do sistema. Se estivermos fora, nos tornamos objetos da caridade, das ações humanitárias. 
Nos anos 70, havia alusão à linguagem de desenvolvimento. Hoje, parece-me que há, oficialmente, a idéia de que uma parte do mundo deve ser objeto de caridade. Não creio que alguém possa dizer, seriamente, que o Mali e o Burandi ascenderão a um futuro razoável, ou a um mesmo status de um país da Europa ou da América do Norte.

Esse mesmo raciocínio aplica-se em escala nacional e local. Por exemplo, em certos países da América Latina, há setores bem desenvolvidos que estão dentro do sistema e há outros que não. Esse fato acontece também nos EUA. Essa divisão entre o sistema e o resto inscreve-se no espaço. Penso nas cidades sul-americanas porque nelas tudo é mais espetacular.

A evolução urbana, em geral, assume o seguinte aspecto: os centros super sofisticados e luxuosos, lugares da alta tecnologia, os condomínios privados, imóveis vigiados confrontados a um pântano de miséria, o que é reforçado pela migração da população rural para a periferia urbana.

A grande tensão do período atual é a oposição entre a globalização econômica e tecnológica, que cobre de redes globais a Terra inteira, e a consciência de pertencimento ao mesmo planeta, com os problemas que implica, tanto no aspecto físico do planeta ou no conjunto da população. Trata-se do contraste, portanto, da uniformização e da desigualdade. Esta é, evidentemente, uma vasta questão, cujos efeitos podemos observar localmente. É este o contexto atual e, portanto, é necessário ter consciência para observar as coisas.

Do lado da globalização, o que me interessa, ultimamente, é o sistema de imagens: da televisão, do simulacro, da espetacularização, do qual o turismo é um exemplo, no universo urbano. Esse universo de imagens... Parece-me haver bons aspectos dessa questão: um que se destina aos indivíduos, enquanto tal - quando se olh a a televisão, por exemplo, um espectador solitário diante das imagens tem a ilusão de estabelecer uma relação. Há, então, algo que dessimboliza a sociedade em proveito de um imaginário pobre - de um tipo de relação entre o indivíduo e o reflexo. Isso corresponde a uma forma de arranjo do mundo em espetáculo, do qual temos inúmeros exemplos: os parques temáticos, a Disneylândia. Há também a relação entre uma parte da humanidade e a outra. Porque o turismo é, essencialmente, uma parte da humanidade que olha a outra como espetáculo. Seja porque privilegiamos o espetáculo natural, ignorando a gente que está no entorno, seja pelo aspecto folclórico e caricatural. O fato é que lugares de ficção, no modelo de Las Vegas, existem em todo o mundo. O turismo não é, como regra geral, a descoberta - não estou me opondo ao turista; estamos todos no mesmo barco. Mas há uma atividade para olhar os outros como para ter ilusões, imagens falsas, muito parciais, que nos dão impressão de descobrir o mundo - o que é um efeito muito perverso.

Aqui o senhor se aproxima dos pensamentos de autores como Jean Baudrillard e Paul Virilio? Na essência, a sua crítica em relação a esses fenômenos converge com a desses autores?

É verdade que me sinto, comparado a Virilio e Baudrillard, mais otimista. É um otimismo relativo. Meu sentimento profundo é o de que a História não está terminada. Há um terreno 
de luta, há contradições, há, em longo termo, a continuidade da história, as coisas vão mudar. Sou hostil à fórmula de Fukuyama ${ }^{1}$ de que a história está concluída. Em outras palavras, ele quer dizer que não há outra fórmula senão a combinação entre a democracia liberal representativa e a economia de mercado. $E^{\prime}$ certo que em muitos países essa fórmula não corresponde a suas realidades. Há, portanto, a violência e a contradição em potência.

Meu otimismo é relativo porque creio que haverá muita violência no mundo. E diria isto antes do atentado de Nova York. A violência é parte da história, eu não sou violento, eu não apelo à violência. Mas esse é um fato que se observa na história. Há mais violência no mundo hoje do que jamais houve - ela é mais eficaz, porque temos os meios melhores e mais performáticos de exercê-la. Esse sistema de tempo, o mundo global e o mundo residual não podem escapar à história: à inversão de situação. Estou convencido de que haverá uma história e penso ser útil um minimo de ação política, para lembrar certos princípios - se o que nos interessa é verdadeiramente o conhecimento e a ciência, se o que nos interessa $e ́$, de uma parte, a exploração do espaço e, de outra parte, o conhecimento dos mecanismos da vida. A questão da divisão da pobreza e da riqueza entre a humanidade é derrisória. É evidente que não podemos dispensar nossas energias tentando destruir os mais pobres em proveito dos mais ricos. São questões que devem ser reguladas. O bom senso não se impõe jamais senão através dos processos históricos.

Creio que Virilio e Baudrillard são mais apressados quando comparados a mim para falar de um fim mais apocalíptico - o que não é um fim da história, mas um tipo de fim do mundo. Não acredito no fim do mundo, nem no fim da história. O que me aborrece é que um dia vou desaparecer e não saberei a seqüência desta história - mas não serei o único.

0 conceito de cidade genérica, formulado por Rem Koolhaas ${ }^{2}$, permite uma aproximação com o de não-lugares, de sua autoria. Em que medida o senhor se posicionaria em relação a este autor? Quais seriam os pontos convergentes e divergentes?

Koolhaas me interessou pela forma como falou da "cidade genérica". Ele próprio realiza a cidade genérica. É muito difícil saber, quando o ouvimos falar, ou quando o lemos, se sua linguagem é cínica ou não: será que ele realiza apenas o que podemos hoje? Será que se posiciona a favor desta realidade... não sei, não li tudo o que ele escreveu, mas em seus textos, há um tipo de ambigüidade. Estou de acordo com ele, no que tange à distinção entre cidade genérica e histórica - complementando o que ele próprio já disse - a cidade histórica tende a tornar-se, ela própria, genérica. É sobre o que trabalho, neste momento, com Gerard Althabes.

0 artigo de Fukuyama, com o título "The end of history" apareceu em 1989, na revista norte-americana The national interest. Em 1992, Fukuyama lançou o livro The end of history and the last man, editado no Brasil com o título $\mathbf{0}$ fim da história e o último homem, trad. Aulyde Soares Rodrigues. Rio de janeiro: Rocco, 1992.

2 KOOLHAAS, Rem. Mutation. Bordeaux: Arc em revê, 2001.

Gerard Althabe (1932-2004). Na época, ele dirigia junto com Marc Augé o Centro de Estudos dos Mundos Contemporâneos. 
O lado histórico das cidades francesas, a cada dia, torna-se objeto de espetáculo, espaços muito protegidos para os turistas. Dito de outra forma, acredito que a urbanização do mundo tende à vulgarização da cidade genérica. $O$ caso de Paris é muito interessante porque aparentemente é uma resistência. Há em Paris os fenômenos, como as feiras, que dão a sensação de vida da cidade, mas é muito relativo.

Paris, como o resto, assemelha-se ao mundo. É inelutável quando mudamos de escala, há pontos demarcáveis no mundo que pertencem ao mundo, ao mesmo planeta.

Em arquitetura, o programa de necessidades é parte do momento conceitual do edifício. Ele é formado por uma diversidade de camadas que variam entre as preocupações de ordem funcional-tecnológica a outras de ordem simbólica. Na leitura de seus textos, percebemos uma grande atenção à arquitetura, privilegiada pela descrição de suas características físicas. Em que medida sua formação de antropólogo contribui em suas descrições?

O encontro com os arquitetos não foi premeditado. É verdade que os antropólogos se interessam pelo papel demiúrgico dos arquitetos e pela sua capacidade, em aparência, de transformar o espaço - o que éfascinante. Tive a oportunidade de encontrar esses profissionais, após ter escrito os Não-lugares. Não imaginava que esse texto pudesse interessar aos arquitetos e artistas. Sem dúvida, eles ai encontram questões atuais, sobre as quais também refletiam. A primeira coisa que me interessou, no caso dos arquitetos, é que eu estava em oposição simétrica a eles. No fundo, tanto os arquitetos quanto os etnólogos estão interessados na relação do espaço e da sociedade. E isso é fundamental, gente como os arquitetos Priste e Valode me interessaram. Fiz um pequeno trabalho sobre a obra deles. Eles fizeram muita arquitetura industrial. É interessante verificar como as relações de trabalho foram pensadas para um grupo como a L'Óreal. Hoje, a arquitetura parece propor questões muito interessantes, porque está ligada à urbanização do planeta. Há os "eventos arquitetônicos", na escala do planeta: a pirâmide de Pei, o Gugenheim de Bilbao, enfim, acontecimentos que reverberam em escala planetária. Tudo interessa ao antropólogo pelo fato de que o imaginário e a imaginação são seus objetos clássicos. Assim, as criações da arquitetura e a progressão das cidades da mesma forma que as imagens da televisão entram no imaginário contemporâneo - elas são, portanto, bons objetos de observação.

Nesse contexto, como o senhor percebe e articula as diferenças entre os domínios do simbólico e do imaginário para as leituras que faz dos mundos contemporâneos?

Há diferença entre o simbólico e o imaginário, mas não posso fazer uma exegese de Lacan e Lévi-Strauss - o que seria muito difícil. Emprego a palavra simbólico no sentido que lhe foi atribuido por Lévi-Strauss. Em sintese: um sistema de relação, o primeiro é a linguagem implicando os indivíduos em si mesmos. A etnologia estuda as relações, portanto o simbólico - seu sentido. Algumas vezes, refiro-me ao "sentido" como sentido social do fato, no qual essas relações são pensadas 
pelos seus termos. O imaginário é o produto da imaginação, podendo referir-se a contos ou imagens, por exemplo. A relação imaginária com as coisas é individual. Tenho uma relação imaginária com o que imagino ou tenho uma relação imaginária com a imagem. Se vejo na televisão indivíduos que me contam coisas tenho com eles uma relação imaginária no sentido de que é uma relação que não se aplica ao outro. É diferente em uma peça de teatro, que pertence ao nosso patrimônio comum, uma tragédia grega, por exemplo, há uma convergência de imaginação em direção a algo comum que nos diz determinada coisa. Há um elo entre os que compartilham esse momento. $O$ que me parece importante é a relação entre o imaginário individual e o imaginário coletivo e entre o imaginário coletivo e o simbólico. O "imaginário" simbólico é a relação explícita entre uns e outros e o imaginário coletivo é o produto de uma imaginação partilhada, o mito, por exemplo. E depois temos o imaginário individual - o que é de cada um que pode se dar na individualidade.

0 senhor escolhe D. Juan como o anti-herói antropológico, descrevendo-o como o indivíduo absoluto que recusa todas as convenções sociais e todos os parâmetros etnológicos: a filiação, a aliança, a religião, a memória, já que D. Juan só amava no amor seu nascimento, isto é, seu próprio renascimento. Em que mediada podemos relacionar essa figura como uma pré-elaboração do conceito de nãolugares ${ }^{4}$ ?
Don Juan é um personagem, um herói pelo qual sempre tive simpatia. Principalmente pelo Don Juan de Molière, porque ele busca as coisas e refuta os valores estabelecidos. Ele não se explica nos termos do cinismo. É o amor à humanidade. Ele parece prefigurar o século XVIII. Tudo aquilo em que eu amaria crer: a liberdade do indivíduo, a solidariedade, e, para evocar a divisa revolucionária, a fraternidade. Fundamentalmente, certa igualdade face à morte. É um personagem que me fascina por sua relação com o tempo. Porque, bem entendido, ele é infiel, mas é fiel a si próprio, aquilo que o atrai é o novo. De certa maneira, podemos imaginar que ele experimenta sempre a mesma coisa-é o que chama o "charme das inclinações nascentes" - quando se apaixona. É uma espécie de vacilo, de frêmito, de sair de si próprio. Se pensarmos em termos desse começo, é um homem que nunca renuncia. Cada vez que ele repete, ele recomeça. Nesse sentido, ele éverdadeiramente um mito. É um mito moderno? Sim, acredito ser um mito do indivíduo, no século XVIII. O que ele teria a ver com a supermodernidade ou a época atual: nós poderíamos relacioná-lo ao consumidor compulsivo, mas isso me desagradaria, pois tenho simpatia por ele - mas, éuma interpretação possível. Creio que, se Don Juan de Molière vivesse hoje, ele não tomaria as coisas seriamente, seria o sacrilégio, o sacrilégio.

Portanto, diante do culto do consumo, diante das evidências que nos acenam ao longo do tempo, através da mídia, creio que D.Juan não seria o homem do consumo. Eu imaginaria o 
D. Juan de hoje como capaz de democratizar o que estamos habituados. Ele procuraria o verdadeiro rito, o rito que pode inaugurar e abrir as coisas. Porque D. Juan não é o homem da repetição simplesmente. Ele não recua jamais. Seria um suicida desesperado - nós o podemos direcionar para muitas coisas, já que é um personagem de teatro. Ele não teria medo de enfrentar aquilo em que não crê.

\section{Bibliografia de Marc Augé}

AUGE, Marc. Le Rivage alladian. Paris: ORSTOM, 1969. Théorie des pouvoirs et idéologie. Paris : Herman, 1975.

Pouvoirs de vie, pouvoirs de mort. Paris :

Flammarion, 1977.

Symbole, fonction, histoire. Paris: Hachette Littérature, 1979.

Génie du Paganisme. Paris: Gallimard, 1982.

La traversée du Luxembourg. Paris: Hachette Littérature, 1985.

Un ethnologue dans le métro. Paris: Rivages 1986. Non-Lieux: introduction à une anthropologie de la surmodernité. Paris: Le Seuil, 1992.

Le sens des autres. Paris: Fayard, 1994.

Domaines et châteaux. Paris: Seuil, 1992.

Pour une anthropologie des mondes

contemporains. Paris: Flammarion, 1999.

. Paris, années trente. Paris: Hazan, 1996.

. Limpossible voyage: le tourisme et ses images.

Paris: Payot \& Rivages, 1997.

Fictions fin de siècle. Paris: Fayard, 2000.

Les formes de l'oubli. Paris: Rivages, 2001.
Journal de guerre.Paris: Galilée, 2003.

Le temps en ruines. Paris: Galilée, 2003.

Pour quoi vivons-nous? Paris: Fayard, 2003.

\section{Obras publicadas em português}

AUGÉ, Marc. Não-lugares: introdução a uma antropologia da supermodernidade. São Paulo: Papirus, 1994.

0 sentido dos outros. Petrópolis: Vozes, 1999. Por uma antropologia dos mundos contemporâneos. Paris: Bertrand Brasil, 1997.

A construção do mundo: religião, representações, ideologia. Lisboa: Edição 70. (Col. Perspectivas do homem).

Os domínios do parentesco: filiação, aliança matrimonial, residência. Lisboa: Edição 70. (Col. Perspectivas do homem). 


\section{Comunication and urban space: interview with the French anthropologist Marc Augé}

\section{Abstract}

This text presents the interview with the anthropologist Marc Augé, held at École des Hautes Études en Sciences Sociales, Paris, when topics like urban anthropology, communication, globalization, and today's tendencies of the anthropological thinking were discussed. There is also a brief curriculum vitae of this important thinker and the complete interview, taking into consideration his relevance to the Communication area, specially concerning the complexity of the contemporary cities.

\section{Keywords}

Communication. Urban culture. Audiovisual. Contemporary city.

\section{Comunicación y espacio urbano: entrevista al antropólogo francés Marc Augé}

\section{Resumen}

Este texto presenta la entrevista con el antropólogo Marc Augé, que se realizó en la École des Hautes en Sciences Sociales, París, cuando se abordaron temas como antropología urbana, comunicación, globalización y tendencias actuales del pensamiento antropológico. Además de la entrevista íntegra con Augé, hay aquí un breve currículum vítae de ese importante pensador, considerándose su relevancia para las áreas de Comunicación, particularmente respecto a la complejidad de las ciudades contemporáneas.

\section{Palabras clave}

Comunicación. Cultura urbana. Audiovisual.

Ciudad contemporánea. 


\section{Expediente}

A revista E-Compós é a publicação científica em formato eletrônico da Associação Nacional dos Programas de Pós-Graduação em Comunicação (Compós). Lançada em 2004, tem como principal finalidade difundir a produção acadêmica de pesquisadores da área de Comunicação, inseridos em instituições do Brasil e do exterior.
E-COMPÓS I www.e-compos.org.br I E-ISSN 1808-2599

Revista da Associação Nacional dos Programas de Pós-Graduação em Comunicação. Brasília, v.11, n.1, jan./abr. 2008.

A identificação das edições, a partir de 2008 passa a ser volume anual com três números.

\section{CONSELHO EDITORIAL}

\section{Afonso Albuquerque}

Universidade Federal Fluminense, Brasil

Alberto Carlos Augusto Klein

Universidade Estadual de Londrina, Brasi

Alex Fernando Teixeira Primo

Universidade Federal do Rio Grande do Sul, Brasi

Alfredo Vizeu

Universidade Federal de Pernambuco, Brasil

Ana Carolina Damboriarena Escosteguy

Pontifícia Universidade Católica do Rio Grande do Sul, Brasil

Ana Silvia Lopes Davi Médola

Universidade Estadual Paulista, Brasil

André Luiz Martins Lemos

Universidade Federal da Bahia, Brasil

Ângela Freire Prysthon

Universidade Federal de Pernambuco, Brasil

Antônio Fausto Neto

Universidade do Vale do Rio dos Sinos, Brasil

Antonio Carlos Hohlfeldt

Pontifícia Universidade Católica do Rio Grande do Sul, Brasil

Arlindo Ribeiro Machado

Universidade de São Paulo, Brasil

César Geraldo Guimarães

Universidade Federal de Minas Gerais, Brasi

Cristiane Freitas Gutfreind

Pontifícia Universidade Católica do Rio Grande do Sul, Brasil

Denilson Lopes

Universidade Federal do Rio de Janeiro, Brasil

Eduardo Peñuela Cañizal

Universidade Paulista, Brasi

Erick Felinto de Oliveira

Universidade do Estado do Rio de Janeiro, Brasil

Francisco Menezes Martins

Universidade Tuiuti do Paraná, Brasil

Gelson Santana

Universidade Anhembi/Morumbi, Brasil

Hector Ospina

Universidad de Manizales, Colômbia

leda Tucherman

Universidade Federal do Rio de Janeiro, Brasil

Itania Maria Mota Gomes

Universidade Federal da Bahia, Brasil

Janice Caiafa

Universidade Federal do Rio de Janeiro, Brasil

Jeder Silveira Janotti Junior

Universidade Federal da Bahia, Brasil
John DH Downing

University of Texas at Austin, Estados Unidos

José Luiz Aidar Prado

Pontifícia Universidade Católica de São Paulo, Brasil

José Luiz Warren Jardim Gomes Braga

Universidade do Vale do Rio dos Sinos, Brasi

Juremir Machado da Silva

Pontifícia Universidade Católica do Rio Grande do Sul, Brasil

Lorraine Leu

University of Bristol, Grã-Bretanha

Luiz Claudio Martino

Universidade de Brasília, Brasil

Maria Immacolata Vassallo de Lopes

Universidade de São Paulo, Brasil

Maria Lucia Santaella

Pontifícia Universidade Católica de São Paulo, Brasil

Mauro Pereira Porto

Tulane University, Estados Unidos

Muniz Sodre de Araujo Cabral

Universidade Federal do Rio de Janeiro, Brasil

Nilda Aparecida Jacks

Universidade Federal do Rio Grande do Sul, Brasil

Paulo Roberto Gibaldi Vaz

Universidade Federal do Rio de Janeiro, Brasil

Renato Cordeiro Gomes

Pontifícia Universidade Católica do Rio de Janeiro, Brasil

Ronaldo George Helal

Universidade do Estado do Rio de Janeiro, Brasil

Rosana de Lima Soares

Universidade de São Paulo, Brasil

Rossana Reguillo

Instituto Tecnológico y de Estudios Superiores do Occidente, México

Rousiley Celi Moreira Maia

Universidade Federal de Minas Gerais, Brasil

Sebastião Carlos de Morais Squirra

Universidade Metodista de São Paulo, Brasil

Simone Maria Andrade Pereira de Sá

Universidade Federal Fluminense, Brasil

Suzete Venturelli

Universidade de Brasília, Brasil

Valério Cruz Brittos

Universidade do Vale do Rio dos Sinos, Brasil

Veneza Mayora Ronsini

Universidade Federal de Santa Maria, Brasil

Vera Regina Veiga França

Universidade Federal de Minas Gerais, Brasil

\section{COMISSÃO EDITORIAL}

Ana Gruszynski I Universidade Federal do Rio Grande do Sul, Brasil João Freire Filho I Universidade Federal do Rio de Janeiro, Brasil Rose Melo Rocha I Escola Superior de Propaganda e Marketing, Brasil

\section{CONSULTORES AD HOC}

Bianca Freire-Medeiros I Fundação Getulio Vargas, Brasil Josimey Costa da Silva I Universidade Federal do Rio Grande do Norte, Brasil Maria Conceição Golobovante I Pontifícia Universidade Católica de São Paulo, Brasil Marlyvan Moraes de Alencar I Centro Universitário SENAC-SP, Brasil Miriam de Souza Rossini I Universidade Federal do Rio Grande do Sul, Brasil Paulo Ribeiro I Pontifícia Universidade Católica do Rio de Janeiro, Brasil Rita Alves de Oliveira I Centro Universitário SENAC, Brasil

REVISÃO DE TEXTO E TRADUÇÃO I Everton Cardoso ASSISTÊNCIA EDITORIAL E EDITORAÇÃO ELETRÔNICA I Raquel Castedo
COMPóS I www.compos.org.br

Associação Nacional dos Programas de Pós-Graduação em Comunicação

Presidente

Erick Felinto de Oliveira

Universidade do Estado do Rio de Janeiro, Brasil erickfelinto@uol.com.br

Vice-presidente

Ana Silvia Lopes Davi Médola

Universidade Estadual Paulista, Brasil

asilvia@faac.unesp.br

Secretária-Geral

Denize Correa Araújo

Universidade Tuiuti do Paraná, Brasil

denizearaujo@hotmail.com 